\title{
Regulation of fibroblast growth factor $15 / 19$ and 21 on metabolism: in the fed or fasted state
}

\author{
Dandan Guan ${ }^{1,2 \dagger}$, Lidan Zhao ${ }^{3 \dagger}$, Daiwen Chen ${ }^{1,2}$, Bing Yu ${ }^{1,2}$ and Jie $\mathrm{Yu}^{1,2^{*}}$
}

\begin{abstract}
Fibroblast growth factor (FGF) 15/19 and FGF21 are two atypical members of FGF19 subfamily that function as hormones. Exogenous FGF15/19 and FGF21 have pharmacological effects, and endogenous FGF15/19 and FGF21 play vital roles in the maintenance of energy homeostasis. Recent reports have expanded the effects of FGF15/19 and FGF21 on carbohydrate and lipid metabolism. However, the regulations of FGF15/19 and FGF21 on metabolism are different. FGF15/19 is mainly secreted from the small intestine in response to feeding, and FGF21 is secreted from the liver in response to extended fasting and from the liver and adipose tissue in response to feeding. In this work, we reviewed the regulatory effects of FGF15/19 and FGF21 on metabolism in the fast and fed states. This information may provide some insight into the metabolic regulation of FGF15/19 and FGF21 in different physiological condition.
\end{abstract}

Keywords: Fibroblast growth factor 15/19, Fibroblast growth factor 21, Fed, Fast, Metabolism

\section{Background}

Fibroblast growth factors (FGFs) are a group of structurally related polypeptides, involved in various biological processes such as neuronal functions, development, differentiation, and metabolism [1-3]. There have been 22 FGFs, FGF1-FGF23, identified in mouse and/or human, among which human FGF19 is the orthologous gene of mouse FGF15. The FGFs can be divided into seven subfamilies according to their gene locus, phylogenetic analyses and action modes [4].

These mammalian subfamilies are also classified into three groups based on their action mechanisms, including the intracellular FGFs, the hormone-like FGFs and the canonical FGFs $[5,6]$ (Table 1). The intracellular subfamily, function as nonsecreted signaling molecules and mainly plays a role in neuronal functions $[7,8]$. The hormone-like subfamily, functions over long distances in an endocrine manner and mainly plays a role in metabolism [6]. Canonical FGFs, function as autocrine and/or

\footnotetext{
*Correspondence: yujie@sicau.edu.cn

†Dandan Guan and Lidan Zhao contributed equally to this work

${ }^{1}$ Animal Nutrition Institute, Sichuan Agricultural University, No. 211

Huimin Road, Wenjiang District, Chengdu 611130, China

Full list of author information is available at the end of the article
}

paracrine in multiple developmental processes [2, 9, 10]. Most FGFs have a high affinity for heparin sulfate in the extracellular matrix except the endocrine FGFs, which include FGF15/19, FGF21, and FGF23, have little or no affinity for heparin sulfate [11].

FGF15/19 is mostly secreted from the small intestine in response to feeding. The expression of FGF21 is induced in multiple organs in response to diverse nutrition stressors, such as fasting and amino acid deprivation [12]. FGF15/19 is secreted from the ileum in response to feeding, it acts as endocrine hormones and takes part in the regulation of glucose and lipid metabolism [13]. After entering the portal venous circulation, FGF15/19 represses bile acid synthesis and gluconeogenesis, promotes glycogen synthesis [14], and stimulates gallbladder filling [15]. Unlike other members in the FGF family, FGF21 is a newly discovered factor for metabolism [5], it lacks heparin-binding domain, and has no effect on promoting mitosis and proliferative activity [16, 17]. In response to fasting, FGF21 expression is induced in the liver $[18,19]$. Secreted FGF21 acts as an endocrine hormone to induce ketogenesis and gluconeogenesis. In response to feeding, FGF21 expression is induced in WAT and liver [20-23]. In WAT, FGF21 acts through 
Table 1 FGFs super family

\begin{tabular}{ll}
\hline FGFs & \\
\hline Intracellular subfamily & FGF11, FGF12, FGF13, FGF14 \\
Endocrine subfamily & FGF15/19, FGF21, FGF23 \\
Canonical subfamily & FGF1/2/5, FGF3/4/6, FGF7/10/22, FGF8/17/18, \\
& FGF9/16/20
\end{tabular}

Fibroblast growth factors (FGFs) are a group of proteins. Currently, the FGF family consists of 22 members that can be classified into three groups and can also be divided into 7 subfamilies

an autocrine mechanism to stimulate PPAR $\gamma$ activity and glucose uptake, and via an endocrine mechanism to repress lipolysis in liver $[14,18,24]$. Therefore, we reviewed the regulatory effects of FGF15/19 and FGF21 on nutrient metabolism in the fast and fed states in the present work.

\section{Receptors of FGF15/19 and FGF21}

FGFs exert their function by binding to their tyrosine kinase receptors, FGF receptors (FGFRs). FGF receptors consist of three extracellular immunoglogulin (Ig)-like domains and a single transmembrane domain [25]. Four FGF receptors, FGFR-1 through FGFR-4, have been identified so far [26]. There are many types of FGFs, which require the diversity of FGFR. However, by alternated splicing, the same FGFR genes could generate a variety of different isoforms [27]. The most variant parts are the extracellular Ig domains. FGFR may lack one Ig domain or use different exon for the same Ig-like domains. There are three types of third Ig domains (IIIa, IIIb, and IIIc). The binding of FGF to its receptor requires proteoglycans, namely heparin or heparin sulfate [28], which protects FGF from degradation and creates a local reservoir of FGF.

In addition to FGFRs, the FGF19 subfamily members need Klotho (KL) or $\beta$ Klotho (KLB) protein as a coreceptor to activate their signaling pathway [3] (Fig. 1). $\mathrm{KL}$ is a single-pass trans-membrane protein, which has two homologous domains in the extracellular domain and a short intracellular tail [29]. KLB is expressed in liver, adipose tissue, pancreas and muscle, whereas $\mathrm{KL}$ is expressed in kidney and intestine [30]. KL was first identified in mice as an age suppressor gene. A defect in KL resulted in multiple ageing-like phenotypes, and KL overexpression extends life span in mice [31]. The study with global KLB-knockout mice showed that KLB is essential for most of the physiological functions of FGF15/19 and FGF21 [30].

FGF19 has low affinity for heparin. KLB is essential for FGF15/19 interaction with FGFRs 1c, 2c, 3c and 4c [30, 32]. KLB appears to stabilize the interaction of this ligand with its receptor, perhaps acting as a surrogate for heparin [33]. FGF15/19 is also able to interact directly with FGFR4 in the absence of KLB in a heparin-dependent manner $[32,34]$. Therefore, FGF19 can activate FGFR4 in a KLB-dependent or heparin-dependent manner [33]. A recent study noted that FGF15/19 binds both FGFR1 and FGFR4 in the presence of KLB with comparable affinity, but not to FGFR1 alone although there is $10 \%$ binding to FGFR4 alone. Like FGF15/19, FGF21 binds to KLB in complex with FGFR1c, 2c, or 3c. FGF21 has much higher affinity to FGFR1 than FGFR4 in the presence of KLB [29].

It has been believed that FGF21 forms complexes with FGFR and KLB to activate downstream signaling pathways [35-37]. However, in vitro experiments show that KLB is indispensable for FGF21 [35, 36]. What causes these controversial results is still unclear. Possible explanations proposed by researches were the specific characteristics of cultured cells and an artificial abundance of KLB or FGF21 by adding them into the medium [38].

Typically, FGF binding to FGFR requires heparin sulfate cofactor that limits the diffusion of FGFs from their site of release, so FGF acts as a paracrine or autocrine factor [39]. However, FGF19 subfamily members have low affinity to heparin sulfate, which allow them to enter the circulation and function as hormones [16]. They have several effects that are similar to those of insulin, including stimulation of glycogen synthesis and suppression of gluconeogenesis [13].

\section{Role of FGF15/19 and FGF21 in metabolism Regulation of FGF15/19 on metabolism}

FGF15/19 is expressed in small intestine under the regulation of bile acid (BA) nuclear receptor farnesoid $\mathrm{X}$ receptor (FXR) [40, 41], and is a negative feedback regulator of BA synthesis and gallbladder filling (Fig. 2).

In response to fasting, BAs are stored in the gallbladder until they are needed for digestion normally [15]. In fed state, BAs are released from the gallbladder into the intestine, bind to and activate FXR, thereby induce expression of FGF19 [42]. In humans, serum FGF19 levels exhibited a rhythm with peaks occurring 90-120 min after the postprandial rise in serum BAs, and the FGF19 peaks in turn preceded the declining phase of BA synthesis [43].

In small intestine, BA induces FGF15/19 expression by activating FXR. FXR induces the expression of small heterodimer partner (SHP) in liver $[44,45]$. However, unlike most nuclear receptors, SHP lacks a DNA-binding domain and binds indirectly to the CYP7A1 promoter [44-46]. Knockout studies in FXR-KO and SHP-KO mice has been demonstrated the significance of the FXR-SHP 
a
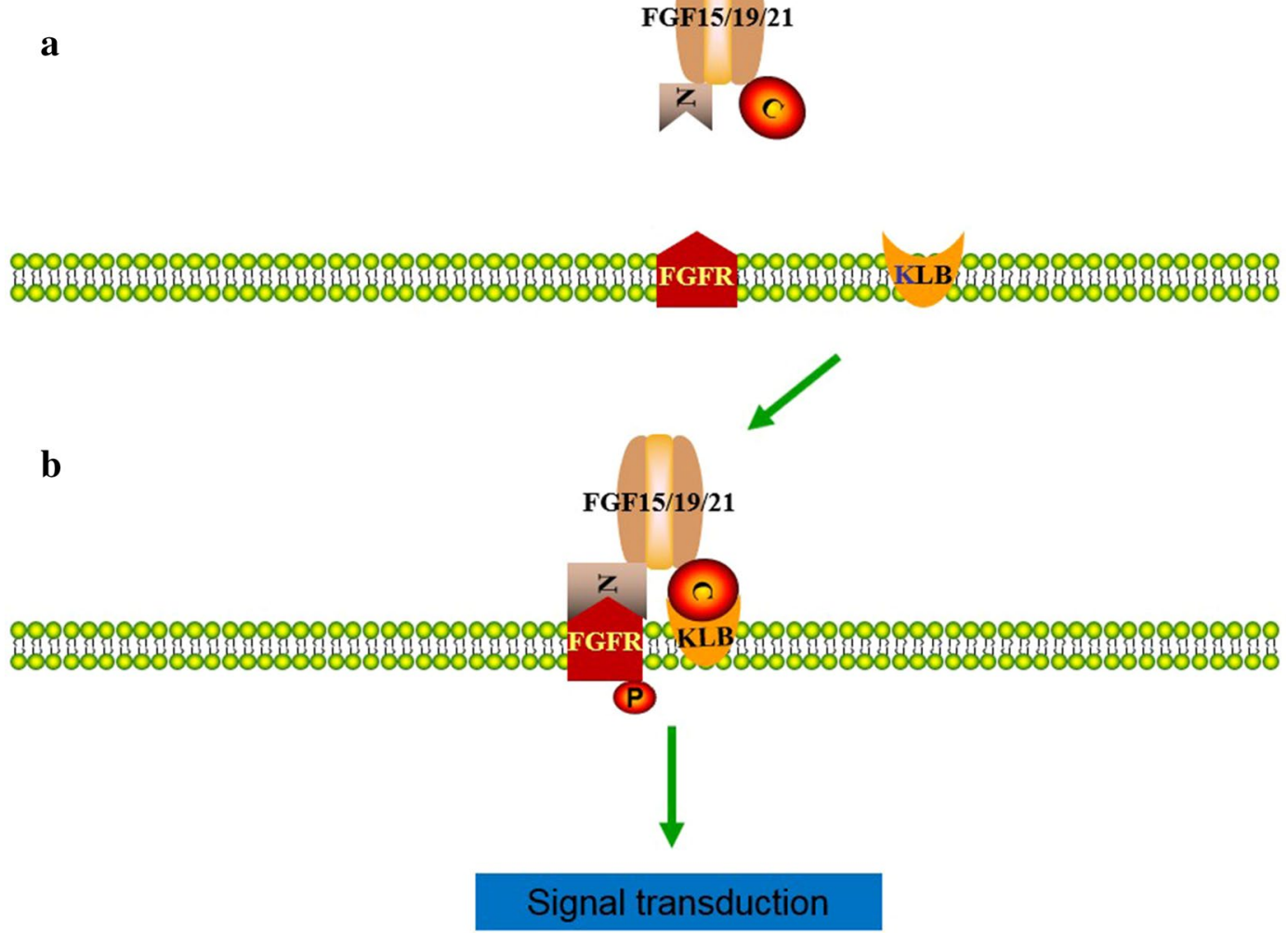

Fig. 1 The mechanism of FGF15/19 and FGF21 receptor activation. a FGFR and KLB that are constitutively associated on the plasma membrane comprise the FGF15/19 and FGF21 receptor, but the receptor is silent without FGF15/19 and FGF21. b Once FGF15/19 and FGF21 come into the vicinity of the receptor, it associates with its receptor. FGF15/19 and FGF21 through its C-terminus bind to KLB, and via its N-terminal part to contact FGFR. Binding of FGF15/19 and FGF21 to FGFR and KLB triggers the receptor phosphorylation, followed by downstream signal transduction and cellular functional responses

pathway in bile acid homeostasis, both of which increase CYP7A1 expression [47-49], the rate-limiting enzyme in the classical BA biosynthetic pathway [14]. FGF15/19 represses CYP7A1 by binding to the FGFR4/KLB receptor complex to activate downstream signaling cascade $[43,50]$. A more recent study showed that an uncharacterized gene, Diet1, transcriptionally and post-transcriptionally influences FGF15/19 level as well as CYP7A1 level, and it co-localize with FGF19 in cultured intestinal cells [51]. This suggests that Diet1 plays a role in FGF15/19 intestine-liver axis involved in the BA synthesis. FGF15/19, a hormone made by the distal small intestine in response to BAs, also promotes relaxation and refilling of the gallbladder after a meal. Cholecystokinin (CCK) is a hormone secreted by duodenum causing gallbladder contraction to release bile, which facilitates lipid digestion. Bile acids travel to ileum, where they induce FGF15 synthesis. FGF15 in turn stimulates gallbladder filling by relaxing smooth muscle in gallbladder [15].
After a meal, besides regulation of BA synthesis and gallbladder filling, FGF15/19 has an effect on glycogen synthesis. FGF15/19 acts on FGFR/KLB receptor complexes to represses cholesterol 7a-hydroxylase (CYP7A1) through small heteromer partner [41, 52], and then increase hepatic glycogen synthase (GS) activity and glycogen synthesis in an insulin-independent manner by inducing the phosphorylation and inactivation of GSK3s [53]. Serum FGF19 levels peak approximately $3 \mathrm{~h}$ after a meal [43] and increase glycogen synthesis by activation of the Ras/ERK pathway; in contrast, serum insulin levels peak within $1 \mathrm{~h}$ after a meal and stimulate glycogen synthesis by the phosphoinositide 3-kinase (Akt) pathway [42].

In addition to glycogen synthesis, FGF15/19 also has an effect on gluconeogenesis. To date, gluconeogenesis inhibition is also differently mediated by FGF19 and insulin by dephosphorylation and inactivation of cAMP response element-binding protein (CREB) and Akt-dependent 


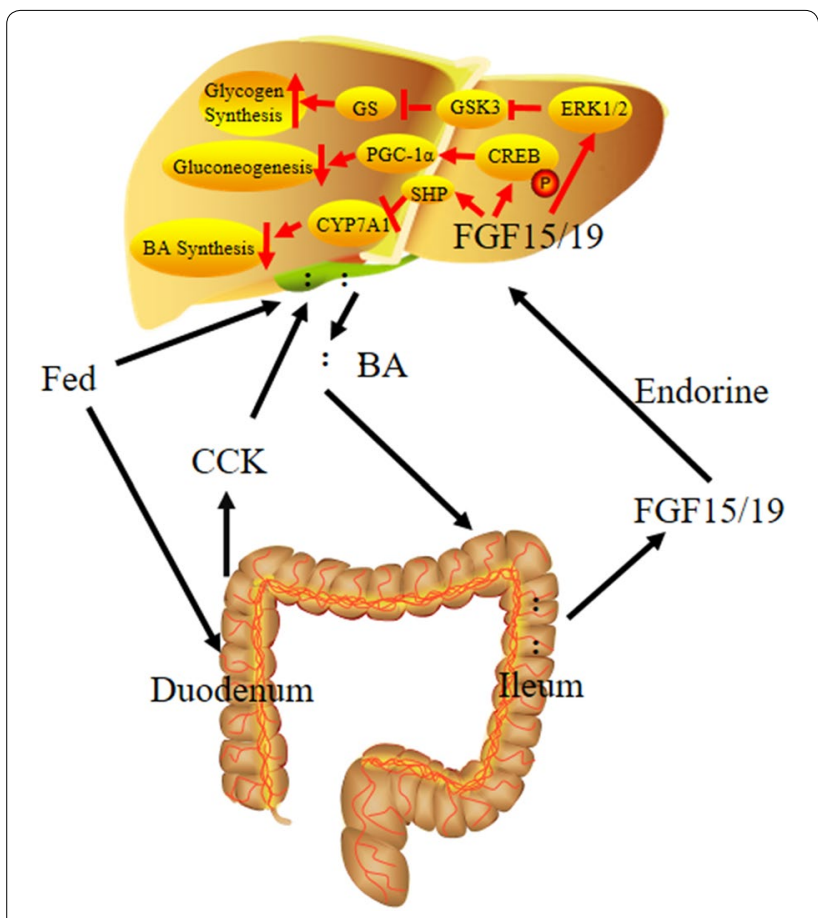

Fig. 2 Endocrine actions of FGF15/19. In fed state, BAs stored in the gallbladder release into the intestine. FGF15/19 expression is induced in the ileum. Secreted FGF15/19 acts on FGFR/KLB receptor complexes via repress CYP7A1 decrease bile acid synthesis, to stimulate glycogen synthase (GS) activity and glycogen synthesis through inactivation of GSK3, and to repress gluconeogenesis by blocking the phosphorylation and activation of CREB

phosphorylation and FoxO1 degradation, respectively [54]. Unlike insulin, FGF15/19 represses gluconeogenesis gene expressions by promoting protein kinase $\mathrm{B}(\mathrm{Akt})$ dependent FOXO1 phosphorylation and dephosphorylation, FGF15/19 cannot activate the PI3K/Akt pathway [42]. The mechanism by which FGF15/19 blocks the expression of gluconeogenesis genes involves dephosphorylation and inactivation of the transcription factor CREB [13]. This in turn down-regulates peroxisome proliferator-activated receptor-1 $\alpha(\mathrm{PGC} 1 \alpha)$ transcription, which subsequently decreases its binding to glucose-6-phosphatase catalytic subunit gene and phosphoenolpyruvate carborykinase gene promoters [13]. Therefore, FGF15/19 inhibits gluconeogenesis via regulating the expression of genes involved in gluconeogenesis.

In fasted status, FGF19 increased the phosphorylation of ERK1 and ERK2 in liver. FGF19 induced phosphorylation of both glycogen synthase kinase (GSK) $3 \alpha$ and GSK3 $\beta$ in animals fasted overnight, which correlated with decreased phosphorylation of $\operatorname{Ser}^{641}$ and $\operatorname{Ser}^{645}$ on glycogen synthase and increased glycogen synthase activity [53]. However, the effects of FGF15/19 and insulin on metabolism in fasted status are noticeable. Although both of them can stimulate glycogen and repress gluconeogenesis, there still are important differences as insulin acts through the insulin receptor-PI3K-Akt pathway, and FGF15/19 mediates its effects through the FGFR/KLBERK pathway. In addition, there are significant temporal differences. In humans, insulin is released minutes after a meal, and in rodent experiments, serum insulin concentrations and its downstream Akt phosphorylation in liver peak approximately $15 \mathrm{~min}$ after a high-carbohydrate or high-fat diet. In contrast, FGF15 mRNA levels in ileum and downstream hepatic ERK1/2 phosphorylation peak about $1 \mathrm{~h}$ after feeding [13]. Likewise, FGF19 serum levels peak near $2 \mathrm{~h}$ after a meal [43], and accordingly, circulating FGF19 levels in humans negatively correlate with fasting glucose levels and metabolic syndrome [55-57]. Thus, FGF15/19 acts after insulin in the transition from the fed to the fasted state.

\section{Regulation of FGF21 on metabolism}

FGF21 is an important regulator of metabolism. A larger number of recent reports have expanded that FGF21 expression is induced in various tissues in response to fasting and feeding. The physiological function of FGF21 in the maintenance of nutritional homeostasis has been suggested (Fig. 3).

Emerging evidences have shown that fasting increases hepatic FGF21 mRNA expression and plasma FGF21 level in mice. Fasting mediated induction of FGF21 requires the peroxisome proliferator-activated receptor a (PPAR $\alpha)[18,58,59]$. PPAR $\alpha$ can bind directly to the FGF21 gene promoter to induce its transcription [18]. It has been shown that fasting-induced FGF21 in liver increases gluconeogenesis, but does not increase glycogenolysis [60]. Gluconeogenesis is controlled by several key enzymes including fructose-1,6-bisphosphatase, glucose-6-phosphatase and phosphoenopyruvate carboxykinase. An acute FGF21 treatment leads to the gene expressions of hepatic glucose-6-phosphatase and phosphoenopyruvate carborykinase [61]. PGC-l $\alpha$ as a transcriptional coactivator regulating gluconeogenic gene is increased after FGF21 treatment [62]. PGC-1 $\alpha$ knockout mice fail to induce glucose-6-phosphatase catalytic subunit and phosphoenopyruvate carboxykinase mRNA expression after FGF21 injection [60]. Taking together, PGC- $1 \alpha$ may play an important role in FGF21 promoting hepatic gluconeogenesis. In contract to those findings, a study using mice with liver-specific deletion of PGC- $1 \alpha$ reveals that liver PGC- $1 \alpha$ is unnecessary in the effects of FGF21 on the gluconeogenesis [61]. The difference results from those two studies can be explained by the mouse models. One is a whole-body PGC- $1 \alpha$ knockout and the other is a liver-specific knockout. It suggests that PGC-1 $\alpha$ expressed in tissues other than liver affects 

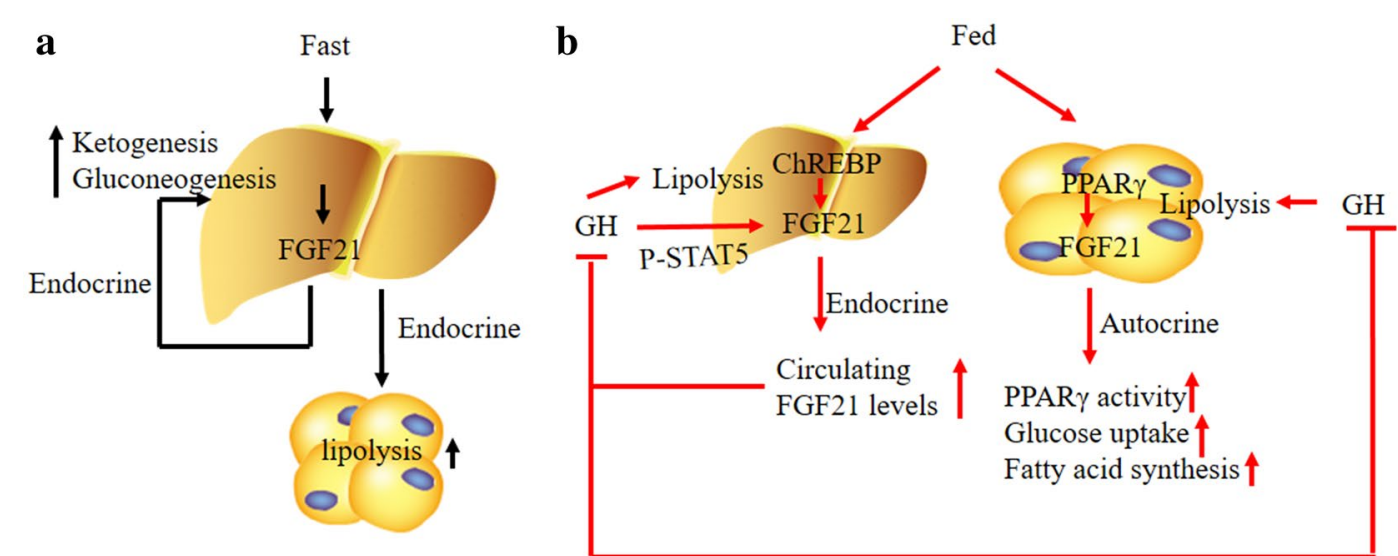

Fig. 3 Physiology actions of FGF21. In response to fasting, FGF21 expression is induced in the liver by the PPARa. Secreted FGF21 acts as an endocrine hormone to induce ketogenesis and gluconeogenesis. In response to feeding, FGF21 expression is induced by the PPARY in WAT and the ChREBP in liver, where FGF21 acts through an autocrine mechanism to stimulate PPARy activity and glucose uptake and to repress lipolysis in liver via an endocrine mechanism

FGF21 regulatory effects on the gluconeogenesis. For example, a study has shown that FGF21 induces PGC-1 $\alpha$ via an indirect mechanism of central nervous system [63]. So the importance of PGC-1 $\alpha$ induction for FGF21 action remains in question $[60,61]$.

Ketone bodies are produced in the liver and delivered to the brain as the major source of energy during fasting period. FGF21 is a molecule regulating lipid metabolism in response to fasting $[18,19]$. Increased FGF21 promotes adipose lipolysis in white adipose tissue in an endocrine manner, and increases the fatty acids transport to the liver where they are directly oxidized for energy production or utilized as a source for ketone body formation [18]. FGF21 transgenic mice have higher serum concentrations of $\beta$-hydroxybutyrate even in the fed state [18]. PPAR $\alpha$ is responsible for coordinating lipid oxidation and ketogenesis in the liver during starvation. Although FGF21 is one of PPAR $\alpha$ target genes, FGF21 induces ketone body production through a mechanism distinct from that previously described for PPAR $\alpha$. As we mentioned above, FGF21 induces ketogenesis by stimulating lipolysis, thereby increasing the supply of free fatty acids to the liver [18, 24]. Both carnitine palmitoyl transferase-1a (CPT-1a) and hydroxymethyl glutaryl-CoA synthase-2 (HMGCS2) are rate-limiting enzymes in ketogenesis [64]. Their genes are directly changed by PPAR $\alpha$ [65]. However, FGF21 cannot regulate their gene expressions, but increases their protein levels through a posttranscriptional mechanism [18].

Mice fed a high-fat, low-carbohydrate ketogenic diet exhibit marked increases in FGF21 expression in the liver $[20,58,66]$ and in white adipose tissue (WAT) by fastingrefeeding regimens $[67,68]$. These responses in the liver and WAT are likely mediated by carbohydrate response element-binding protein and PPAR $\gamma$, respectively [20-23]. Notably, unlike the fasting response that elicits FGF21 release from the liver into circulation, feeding induction of FGF21 in WAT do not cause a corresponding increase in circulating levels of FGF21, so FGF21 secreted by adipose tissue promotes fatty acid synthesis in adipose tissue in a paracrine or autocrine manner [68], and liver generated FGF21 promotes adipose lipolysis in white adipose tissue in an endocrine manner [18]. So FGF21 regulates lipogenesis and lipolysis by distinct modes. Recent studies found that FGF21 acts as a negative feedback signal to terminate $\mathrm{GH}$-stimulated lipolysis in adipocytes and hepatocytes. In the liver, $\mathrm{GH}$ stimulates transcription of the FGF21 through the signal transducer and activator of transcription 5 (STAT 5) signaling pathway $[69,70]$.

\section{Conclusions and implications}

FGF15/19 and FGF21 acting on the heels of metabolic regulation factors to regulate metabolism in response to nutritional status. FGF15/19 is secreted in response to feeding. FGF21 is induced in response to diverse nutrition stressors, especially fasting. Therefore, they can be considered "late-acting" fed- and fasted-state hormones respectively. So we conclude that FGF15/19 and FGF21 play significant roles in coordinating nutrition homeostasis under a variety of physiological conditions.

Both FGF15/19 and FGF21 have distinct physiological effects on nutrient metabolism, though they belong to the same subfamily. FGF15/19 mainly regulates gallbladder filling, bile acid synthesis, and inhibits hepatic gluconeogenesis and lipogenesis in fed state, whereas FGF21 regulates glucose uptake, glycogen synthesis, and ketogenesis in the fed/fast state. Interestingly, it has been shown that 
FGF15/19 and FGF21 have potential roles in metabolic diseases, such as nonalcoholic fatty liver disease, bile acid diarrhea, cardiovascular disease and diabetes. Given the high variability in inter-individuals and interspecies, further studies are urgently needed to evaluate the legitimate therapeutic roles of FGF15/19 and FGF21 in malnutrition associated diseases.

\begin{abstract}
Abbreviations
FGF: fibroblast growth factor; GFGR: fibroblast growth factor receptor; KL: Klotho; KLB: ßKlotho; GS: glycogen synthase; GSK: glycogen synthase kinase; CYP7A1: cholesterol 7a-hydroxylase; Akt: protein kinase B; PI3K: phosphatidylinositol 3-kinase; CREB: CAMP response element-binding protein; PGC-1a: peroxisome proliferator-activated receptor-1a; FXR: farnesoid X receptor; lg: immunoglogulin; ERK: extracellular regulated protein kinases; CCK: cholecystokinin; STAT 5: signal transducer and activator of transcription 5; SHP: small heterodimer partner; PPARa: peroxisome proliferator-activated receptor a; GH: growth hormone; WAT: white adipose tissue; CPT-1a: carnitine palmitoyl transferase-1a; HMGCS2: hydroxymethyl glutaryl-CoA synthase-2.
\end{abstract}

\section{Authors' contributions}

$D G$ and $L Z$ contributed to the literature search, synthesis of information and preparation of the manuscript. DC and BY were involved in refining the study design and literature search. JY critically reviewed, edited and revised the manuscript. All authors read and approved the final manuscript.

\section{Author details}

${ }^{1}$ Animal Nutrition Institute, Sichuan Agricultural University, No. 211 Huimin Road, Wenjiang District, Chengdu 611130, China. ${ }^{2}$ Key Laboratory for Animal Disease-Resistance Nutrition of China Ministry of Education, Sichuan Agricultural University, Chengdu 611130, China. ${ }^{3}$ Department of Animal and Poultry Sciences, Virginia Polytechnic Institute and State University, Blacksburg, VA 24061, USA.

\section{Acknowledgements}

This work was supported by Key Project from Sichuan Department of Education (13ZA0261) and National Key Basic Research Program of China (2012CB124701)

\section{Competing interests}

The authors declare that they have no competing interests.

Received: 28 December 2015 Accepted: 23 February 2016 Published online: 01 March 2016

\section{References}

1. Itoh N. Hormone-like (endocrine) Fgfs: their evolutionary history and roles in development, metabolism, and disease. Cell Tissue Res. 2010;342:1-11.

2. Beenken A, Mohammadi M. The FGF family: biology, pathophysiology and therapy. Nat Rev Drug Discov. 2009;8:235-53.

3. Itoh N, Ohta H, Konishi M. Endocrine FGFs: evolution, physiology, pathophysiology, and pharmacotherapy. Front Endocrinol (Lausanne). 2015;6:154.

4. Presta M. Dell'Era P, Mitola S, Moroni E, Ronca R, Rusnati M: fibroblast growth factor/fibroblast growth factor receptor system in angiogenesis. Cytokine Growth Factor Rev. 2005;16:159-78.

5. Itoh N, Ornitz DM. Evolution of the Fgf and Fgfr gene families. Trends Genet. 2004;20:563-9.

6. Itoh N, Ornitz DM. Functional evolutionary history of the mouse Fgf gene family. Dev Dyn. 2008;237:18-27.

7. Goldfarb M, Schoorlemmer J, Williams A, Diwakar S, Wang Q, Huang X, Giza J, Tchetchik D, Kelley K, Vega A, et al. Fibroblast growth factor homologous factors control neuronal excitability through modulation of voltage-gated sodium channels. Neuron. 2007;55:449-63.
8. Goldfarb M. Fibroblast growth factor homologous factors: evolution, structure, and function. Cytokine Growth Factor Rev. 2005;16:215-20.

9. Cicione C, Degirolamo C, Moschetta A. Emerging role of fibroblast growth factors 15/19 and 21 as metabolic integrators in the liver. Hepatology. 2012;56:2404-11.

10. Itoh N, Ornitz DM. Fibroblast growth factors: from molecular evolution to roles in development, metabolism and disease. J Biochem. 2011;149:121-30.

11. Owen BM, MangelsdorfDJ, Kliewer SA. Tissue-specific actions of the metabolic hormones FGF15/19 and FGF21. Trends Endocrinol Metab. 2015;26:22-9.

12. Zhang F, Yu L, Lin X, Cheng P, He L, Li X, Lu X, Tan Y, Yang H, Cai L. Minireview: roles of fibroblast growth factors 19 and 21 in metabolic regulation and chronic diseases. Mol Endocrinol. 2015;29:1400-13.

13. Potthoff MJ, Boney-Montoya J, Choi M, He T, Sunny NE, Satapati S, Suino-Powell K, Xu HE, Gerard RD, Finck BN. FGF15/19 regulates hepatic glucose metabolism by inhibiting the CREB-PGC-1 a pathway. Cell Metab. 2011;13:729-38.

14. Potthoff MJ, Kliewer SA, Mangelsdorf DJ. Endocrine fibroblast growth factors 15/19 and 21: from feast to famine. Genes Dev. 2012;26:312-24.

15. Choi M, Moschetta A, Bookout AL, Peng L, Umetani M, Holmstrom SR, Suino-Powell K, Xu HE, Richardson JA, Gerard RD. Identification of a hormonal basis for gallbladder filling. Nat Med. 2006;12:1253-5.

16. Goetz R, Beenken A, Ibrahimi OA, Kalinina J, Olsen SK, Eliseenkova AV, Xu C, Neubert TA, Zhang F, Linhardt RJ, et al. Molecular insights into the klotho-dependent, endocrine mode of action of fibroblast growth factor 19 subfamily members. Mol Cell Biol. 2007;27:3417-28.

17. Kharitonenkov A, Shiyanova TL, Koester A, Ford AM, Micanovic R, Galbreath EJ, Sandusky GE, Hammond LJ, Moyers JS, Owens RA, et al. FGF-21 as a novel metabolic regulator. J Clin Invest. 2005;115:1627-35.

18. Inagaki T, Dutchak P, Zhao G, Ding X, Gautron L, Parameswara V, Li Y, Goetz R, Mohammadi M, Esser $V$, et al. Endocrine regulation of the fasting response by PPARalpha-mediated induction of fibroblast growth factor 21. Cell Metab. 2007;5:415-25.

19. Galman C, Lundasen T, Kharitonenkov A, Bina HA, Eriksson M, Hafstrom I, Dahlin M, Amark P, Angelin B, Rudling M. The circulating metabolic regulator FGF21 is induced by prolonged fasting and PPARalpha activation in man. Cell Metab. 2008;8:169-74.

20. Ma L, Robinson LN, Towle HC. ChREBP*Mlx is the principal mediator of glucose-induced gene expression in the liver. J Biol Chem. 2006;281:28721-30.

21. Muise ES, Azzolina B, Kuo DW, El-Sherbeini M, Tan Y, Yuan X, Mu J, Thompson JR, Berger JP, Wong KK. Adipose fibroblast growth factor 21 is up-regulated by peroxisome proliferator-activated receptor gamma and altered metabolic states. Mol Pharmacol. 2008;74:403-12.

22. Wang H, Qiang L, Farmer SR. Identification of a domain within peroxisome proliferator-activated receptor gamma regulating expression of a group of genes containing fibroblast growth factor 21 that are selectively repressed by SIRT1 in adipocytes. Mol Cell Biol. 2008;28:188-200.

23. lizuka K, Takeda J, Horikawa Y. Glucose induces FGF21 mRNA expression through ChREBP activation in rat hepatocytes. FEBS Lett. 2009;583:2882-6.

24. Hotta Y, Nakamura H, Konishi M, Murata Y, Takagi H, Matsumura S, Inoue K, Fushiki T, Itoh N. Fibroblast growth factor 21 regulates lipolysis in white adipose tissue but is not required for ketogenesis and triglyceride clearance in liver. Endocrinology. 2009;150:4625-33.

25. Lee $\mathrm{PL}$, Johnson DE, Cousens LS, Fried VA, Williams LT. Purification and complementary DNA cloning of a receptor for basic fibroblast growth factor. Science. 1989;245:57-60.

26. Johnson DE, Williams LT. Structural and functional diversity in the FGF receptor multigene family. Adv Cancer Res. 1993;60:1-41.

27. Powers CJ, McLeskey SW, Wellstein A. Fibroblast growth factors, their receptors and signaling. Endocr Relat Cancer. 2000;7:165-97.

28. Ornitz DM. FGFs, heparan sulfate and FGFRs: complex interactions essential for development. Bioessays. 2000;22(2):108-12.

29. Yang C, Jin C, Li X, Wang F, McKeehan WL, Luo Y. Differential specificity of endocrine FGF19 and FGF21 to FGFR1 and FGFR4 in complex with KLB. PLOS ONE. 2012;7:e33870.

30. Kurosu H, Choi M, Ogawa Y, Dickson AS, Goetz R, Eliseenkova AV, Mohammadi M, Rosenblatt KP, Kliewer SA, Kuro-o M. Tissue-specific expression of betaKlotho and fibroblast growth factor (FGF) receptor isoforms determines metabolic activity of FGF19 and FGF21. J Biol Chem. 2007:282:26687-95. 
31. Kuro-o M, Matsumura Y, Aizawa H, Kawaguchi H, Suga T, Utsugi T, Ohyama Y, Kurabayashi M, Kaname T, Kume E, et al. Mutation of the mouse klotho gene leads to a syndrome resembling ageing. Nature. 1997;390:45-51.

32. Lin BC, Wang M, Blackmore C, Desnoyers LR. Liver-specific activities of FGF19 require Klotho beta. J Biol Chem. 2007;282:27277-84.

33. Lin BC, Desnoyers LR. FGF19 and cancer endocrine FGFs and Klothos. Springer US. 2012;73:183-94.

34. Wu X, Ge H, Lemon B, Weiszmann J, Gupte J, Hawkins N, Li X, Tang J, Lindberg R, Li Y. Selective activation of FGFR4 by an FGF19 variant does not improve glucose metabolism in ob/ob mice. Proc Natl Acad Sci USA 2009;106:14379-84.

35. Suzuki M, Uehara Y, Motomura-Matsuzaka K, Oki J, Koyama Y, Kimura M, Asada M, Komi-Kuramochi A, Oka S, Imamura T. betaKlotho is required for fibroblast growth factor (FGF) 21 signaling through FGF receptor (FGFR) 1c and FGFR3c. Mol Endocrinol. 2008;22:1006-14.

36. Ogawa Y, Kurosu H, Yamamoto M, Nandi A, Rosenblatt KP, Goetz R, Eliseenkova AV, Mohammadi M, Kuro-o M. BetaKlotho is required for metabolic activity of fibroblast growth factor 21. Proc Natl Acad Sci USA. 2007;104:7432-7.

37. Yie J, Hecht R, Patel J, Stevens J, Wang W, Hawkins N, Steavenson S, Smith S, Winters D, Fisher S, et al. FGF21 N- and C-termini play different roles in receptor interaction and activation. FEBS Lett. 2009;583:19-24.

38. Tomiyama K, Maeda R, Urakawa I, Yamazaki Y, Tanaka T, Ito S, Nabeshima Y, Tomita T, Odori S, Hosoda K, et al. Relevant use of Klotho in FGF19 subfamily signaling system in vivo. Proc Natl Acad Sci USA. 2010;107:1666-71.

39. Asada M, Shinomiya M, Suzuki M, Honda E, Sugimoto R, Ikekita M, Imamura T. Glycosaminoglycan affinity of the complete fibroblast growth factor family. Biochim Biophys Acta. 2009;1790:40-8.

40. Holt JA, Luo G, Billin AN, Bisi J, McNeill YY, Kozarsky KF, Donahee M, Wang DY, Mansfield TA, Kliewer SA, et al. Definition of a novel growth factordependent signal cascade for the suppression of bile acid biosynthesis. Genes Dev. 2003;17:1581-91.

41. Inagaki $T$, Choi M, Moschetta A, Peng L, Cummins CL, McDonald JG, Luo G, Jones SA, Goodwin B, Richardson JA, et al. Fibroblast growth factor 15 functions as an enterohepatic signal to regulate bile acid homeostasis. Cell Metab. 2005;2:217-25.

42. Kir S, Kliewer SA, Mangelsdorf DJ. Roles of FGF19 in liver metabolism. Cold Spring Harb Symp Quant Biol. 2011;76:139-44.

43. Lundasen T, Galman C, Angelin B, Rudling M. Circulating intestinal fibroblast growth factor 19 has a pronounced diurnal variation and modulates hepatic bile acid synthesis in man. J Intern Med. 2006;260:530-6.

44. Goodwin B, Jones SA, Price RR, Watson MA, Mckee DD, Moore LB, et al. A regulatory cascade of the nuclear receptors FXR, SHP-1, and $L R H-1$ represses bile acid biosynthesis. Mol Cell. 2000;6(3):517-26.

45. Lu TT, Makishima M, Repa JJ, Schoonjans K, Keer TA, Auwerx J, et al. Molecular basis for feedback regulation of bile acid synthesis by nuclear receptors. Mol Cell. 2000;6(3):507-15.

46. De Fabiani E, Mitro N, Anzulovich AC, Pinelli A, Galli G, Crestani M. The negative effects of bile acids and tumor necrosis factor-alpha on the transcription of cholesterol 7alpha-hydroxylase gene (CYP7A1) converge to hepatic nuclear factor-4: a novel mechanism of feedback regulation of bile acid synthesis mediated by nuclear receptors. J Biol Chem. 2001;276:30708-16

47. Kerr TA, Saeki S, Schneider M, Schaefer K, Berdy S, Redder T, et al. Loss of nuclear receptor SHP impairs but does not eliminate negative feedback regulation of bile acid synthesis. Dev Cell. 2002;2(6):713-20.

48. Wang L, Lee YK, Bundman D, Han Y, Thevananther S, Kim C, et al. Redundant pathways for negative feedback regulation of bile acid production. Dev Cell. 2002;2(6):721-31.

49. Kok T, Hulzebos CV, Wolters H, Havinga R, Agellon LB, Stellaard F, Shan B, Schwarz M, Kuipers F. Enterohepatic circulation of bile salts in farnesoid $X$ receptor-deficient mice: efficient intestinal bile salt absorption in the absence of ileal bile acid-binding protein. J Biol Chem. 2003;278:41930-7.

50. Song KH, LiT, Owsley E, Strom S, Chiang JY. Bile acids activate fibroblast growth factor 19 signaling in human hepatocytes to inhibit cholesterol 7alpha-hydroxylase gene expression. Hepatology. 2009:49:297-305.

51. Vergnes L, Lee JM, Chin RG, Auwerx J, Reue K. Diet1 functions in the FGF15/19 enterohepatic signaling axis to modulate bile acid and lipid levels. Cell Metab. 2013;17:916-28.
52. Kim I, Ahn SH, Inagaki T, Choi M, Ito S, Guo GL, Kliewer SA, Gonzalez FJ. Differential regulation of bile acid homeostasis by the farnesoid $X$ receptor in liver and intestine. J Lipid Res. 2007;48:2664-72.

53. Kir S, Beddow SA, Samuel VT, Miller P, Previs SF, Suino-Powell K, Xu HE, Shulman Gl, Kliewer SA, Mangelsdorf DJ. FGF19 as a postprandial, insulin-independent activator of hepatic protein and glycogen synthesis. Science. 2011;331:1621-4.

54. Shin DJ, Osborne TF. FGF15/FGFR4 integrates growth factor signaling with hepatic bile acid metabolism and insulin action. J Biol Chem. 2009;284:11110-20.

55. Stejskal D, Karpisek M, Hanulova Z, Stejskal P. Fibroblast growth factor-19: development, analytical characterization and clinical evaluation of a new ELISA test. Scand J Clin Lab Invest. 2008;68:501-7.

56. Reiche M, Bachmann A, Lossner U, Bluher M, Stumvoll M, Fasshauer M. Fibroblast growth factor 19 serum levels: relation to renal function and metabolic parameters. Horm Metab Res. 2010;42:178-81.

57. Mráz M, Lacinová Z, Kaválková P, Haluziková D, Trachta P, Drápalová J, et al. Serum concentrations of fibroblast growth factor 19 in patients with obesity and type 2 diabetes mellitus: the influence of acute hyperinsulinemia, very-low calorie diet and PPAR-alpha agonist treatment. Physiol Res. 2011;60(4):627-36.

58. Badman MK, Pissios P, Kennedy AR, Koukos G, Flier JS, Maratos-Flier E. Hepatic fibroblast growth factor 21 is regulated by PPARalpha and is a key mediator of hepatic lipid metabolism in ketotic states. Cell Metab. 2007;5:426-37.

59. Lundasen T, Hunt MC, Nilsson LM, Sanyal S, Angelin B, Alexson SE, Rudling M. PPARalpha is a key regulator of hepatic FGF21. Biochem Biophys Res Commun. 2007;360:437-40.

60. Potthoff MJ, Inagaki T, Satapati S, Ding X, He T, Goetz R, Mohammadi $M$, Finck BN, Mangelsdorf DJ, Kliewer SA, Burgess SC. FGF21 induces PGC-1alpha and regulates carbohydrate and fatty acid metabolism during the adaptive starvation response. Proc Natl Acad Sci USA. 2009:106:10853-8.

61. Fisher FM, Estall JL, Adams AC, Antonellis PJ, Bina HA, Flier JS, Kharitonenkov A, Spiegelman BM, Maratos-Flier E. Integrated regulation of hepatic metabolism by fibroblast growth factor 21 (FGF21) in vivo. Endocrinology. 2011;152:2996-3004.

62. Yoon JC, Puigserver P, Chen GX, Donovan J, Wu ZD, Rhee J, Adelmant G, Stafford J, Kahn CR, Granner DK, et al. Control of hepatic gluconeogenesis through the transcriptional coactivator PGC-1. Nature. 2001;413:131-8.

63. Sarruf DA, Thaler JP, Morton GJ, German J, Fischer JD, Ogimoto K, Schwartz MW. Fibroblast growth factor 21 action in the brain increases energy expenditure and insulin sensitivity in obese rats. Diabetes. 2010;59:1817-24.

64. Hegardt FG. Mitochondrial 3-hydroxy-3-methylglutaryl-CoA synthase: a control enzyme in ketogenesis. Biochem J. 1999;338(Pt 3):569-82.

65. Erol E, Kumar LS, Cline GW, Shulman GI, Kelly DP, Binas B. Liver fatty acid-binding protein is required for high rates of hepatic fatty acid oxidation but not for the action of PPAR-alpha in fasting mice. Faseb J. 2003;17:347.

66. Uebanso T, Taketani Y, Yamamoto H, Amo K, Ominami H, Arai H, Takei Y, Masuda M, Tanimura A, Harada N, et al. Paradoxical regulation of human FGF21 by both fasting and feeding signals: is FGF21 a nutritional adaptation factor? PLoS ONE. 2011;6:e22976.

67. Oishi K, Konishi M, Murata Y, Itoh N. Time-imposed daily restricted feeding induces rhythmic expression of Fgf21 in white adipose tissue of mice. Biochem Biophys Res Commun. 2011;412:396-400.

68. Dutchak PA, Katafuchi T, Bookout AL, Choi JH, Yu RT, Mangelsdorf DJ, Kliewer SA. Fibroblast growth factor-21 regulates PPARgamma activity and the antidiabetic actions of thiazolidinediones. Cell. 2012;148:556-67.

69. Chen W, Hoo RL, Konishi M, Itoh N, Lee PC, Ye HY, Lam KS, Xu A. Growth hormone induces hepatic production of fibroblast growth factor 21 through a mechanism dependent on lipolysis in adipocytes. J Biol Chem. 2011;286:34559-66.

70. Yu J, Zhao L, Wang A, Eleswarapu S, Ge X, Chen D, Jiang H. Growth hormone stimulates transcription of the fibroblast growth factor 21 gene in the liver through the signal transducer and activator of transcription 5. Endocrinology. 2012;153:750-8. 